Open Access

\title{
The academic firm: a new design and redesign proposition for entrepreneurship in innovation-driven knowledge economy

\author{
David F. J. Campbell ${ }^{1,2^{*}}$ and Elias G. Carayannis ${ }^{3}$
}

\author{
* Correspondence: david.campbell@ \\ aau.at; david.campbell@uni-klu.ac.at; \\ david.campbell@univie.ac.at \\ ${ }^{1}$ Institute of Science \\ Communication and Higher \\ Education Research, \\ Alpen-Adria-University Klagenfurt, \\ Vienna, Austria \\ 2University of Applied Arts, Vienna, \\ Austria \\ Full list of author information is \\ available at the end of the article
}

\begin{abstract}
The academic firm is a type of firm (firm-based organization or institution) that is being driven by focusing on encouraging, supporting, and advancing knowledge production (research, research and experimental development, R\&D) and knowledge application (innovation). The academic firm interprets and qualifies a disciplinary (interdisciplinary) variety of the background of its employees (and their competences) as a potential opportunity and asset to perform creatively in knowledge production and knowledge application. The academic firm has an interest to engage in networks with universities (higher education institutions) or other academic research institutions, driven out of a desire to access university knowledge (for example, basic university research). In general, the academic firm values engagement in diversified networks as a form for creating knowledge as well as benefitting from opportunities. The academic firm accepts in principle, in certain situations even promotes, split employment or "cross-employment" (multi-employment) of its employees with other (academic) organizations or institutions, for example universities or other higher education institutions. The proposition here is that the academic firm represents a new design (and redesign) for entrepreneurship in innovation-driven knowledge economy.

Keywords: Academic firm, Commercial firm, Creativity, Cross-employment, Crossretirement, Design, Entrepreneurship, Innovation, Knowledge application, Knowledge economy, Knowledge production, Linear innovation, Networks, Non-linear innovation, Redesign, Research (R\&D)
\end{abstract}

\section{Background}

The "academic firm" represents a type of firm (firm-based organization) that focuses on encouraging, supporting, and advancing knowledge production (research, research and experimental development, $R \& D$ ) and knowledge application (innovation). The academic firm is also inclined to generate profit (revenues) but follows here more the logic of a "sustainability" in balance with knowledge production and the principles of knowledge production. The contrary concept to the academic firm would be the "commercial firm," which is primarily being motivated and driven out of an interest of maximizing profit (revenues). Between these two conceptual poles of understanding, there are various possibilities of a gradual or also unconventional (radical) combination of principles for the empirical organization of a concrete firm, its organizational manifestation. The shortcut for a definition therefore is: "The Commercial Firm 
concentrates on maximizing or optimizing profit, whereas the Academic Firm focuses on maximizing or optimizing knowledge and innovation" (Carayannis and Campbell 2012, p. 27).

\section{Design and redesign of the academic firm}

Knowledge and innovation are crucial key drivers for the academic firm. Academic firms can follow the logic of linear innovation but also the logic of non-linear innovation. The model of linear innovation often is being assigned to Bush (1945). This model assumes a sequential "first-then" relationship, where there is a first basic research at universities that gradually diffuses out into society and economy and where firms then translate the lines of basic research into application and economic as well as commercial uses and profits. But non-linear innovation favors a different approach. Non-linear innovation is interested in a more direct and parallel coupling of knowledge production and knowledge application, where there are mutual interferences and parallel as well as parallelized interactions between basic research and knowledge application. The organization of non-linear innovation encourages creative organizational designs (Campbell and Carayannis 2012). In context of firm-based organizations, also for the academic firm, the processing and advancement of non-linear innovation may imply the following: (1) firms (academic firms) engage simultaneously in different technology life cycles at different levels of technology maturity; (2) firms (academic firms) accept to a certain extent, even encourage, cross-employment of their employees with other institutions, for example, academic institutions, such as universities or other higher education institutions. Cross-employment, as a concept, identifies forms and varieties of multi-employment, where an individual person is being simultaneously employed by more than one organization (by at least two organizations): should those organizations also root in different sectors, then cross-employment displays characteristics of a trans-sectoral network-building (Campbell 2011).

Academic firms express a particular interest to network with universities, other higher education institutions, university-related institutions, and all forms and manifestations of organizations that conduct an academically based-type of research or basic research. Academic firms explore also possibilities, options, and opportunities of networking with other firms (academic firms, but also commercial firms). There always remains the challenge, how to balance and how to refer to each other (out of the perspective of the firms) with regard to cooperation and competition. Furthermore, networks can integrate aspects of cooperation and competition. The organizational design of patterns of cooperation and competition allows creativity and can also be captured and described by the notion and concept of "co-opetition" (Brandenburger and Nalebuff 1997) (see Fig. 1).

Knowledge production in context of universities and the higher education system has been explained on the basis of the models of "mode 1" and "mode 2" of knowledge production. Mode 1 emphasizes a traditional understanding and refers to university basic research, with no particular interest in knowledge application, and being organized in context of academic disciplines. Here, the established peers of the academic disciplines define and decide on quality (acceptance and rejection of work). Mode 2 already expresses a greater interest in knowledge application and is characterized by 


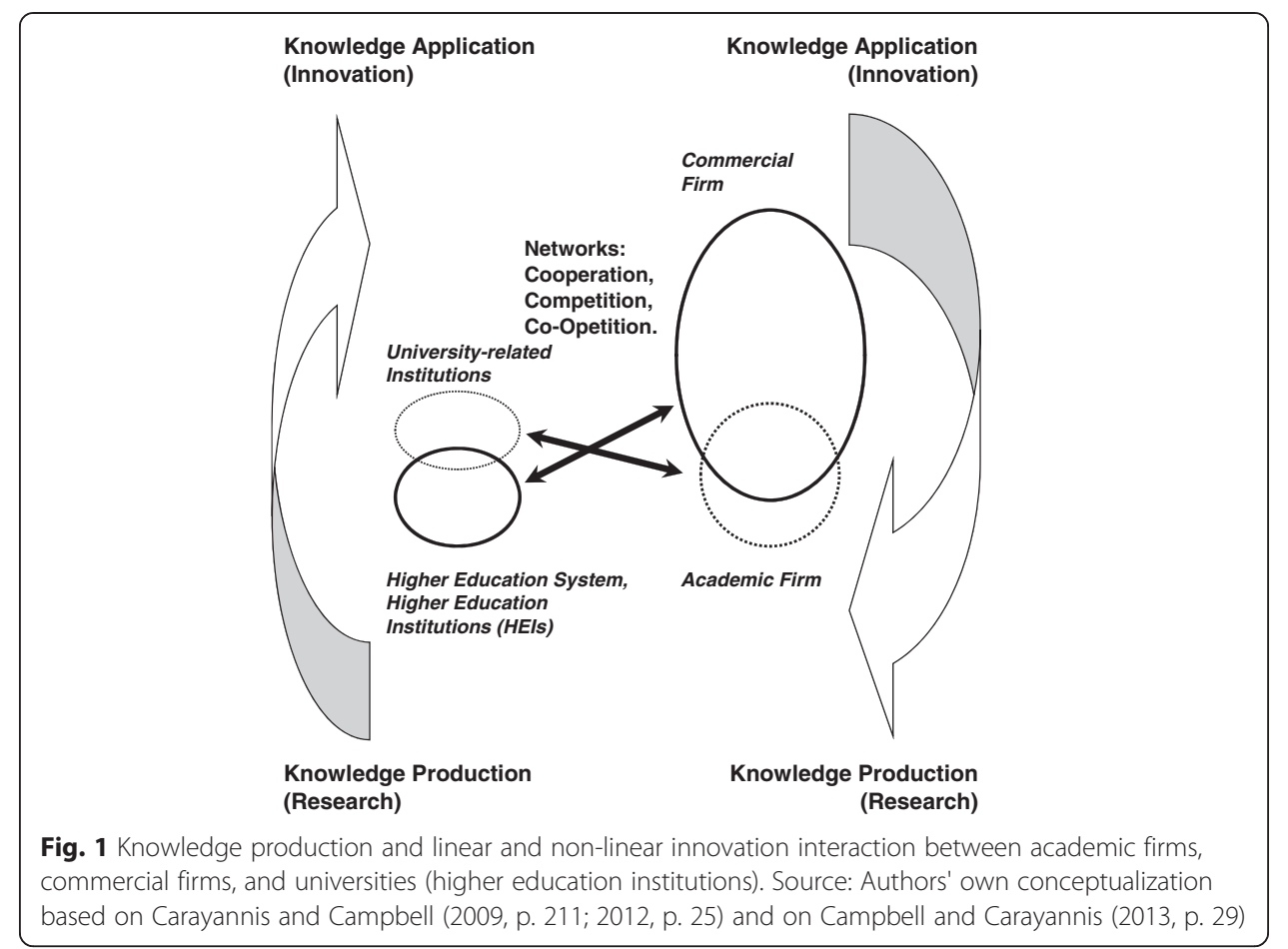

the following principles: "knowledge produced in the context of application"; "transdisciplinarity"; "heterogeneity and organizational diversity"; "social accountability and reflexivity"; and finally "quality control" (Gibbons et al. 1994, pp. 3-8, 167; see furthermore Nowotny et al. 2001, 2003, 2006). "Mode 3" universities or higher education institutions are inclined to seek and to explore creative, novel, and innovative combinations of mode 1 and mode 2. One key interest of mode 3 is "basic research in the context of application" (Campbell and Carayannis 2013, p. 34). Mode 2 as well as mode 3 universities clearly meet and fulfill some of the characteristics of the "entrepreneurial university." However, it is important to realize that a mode 3 university is more than an entrepreneurial university, in the sense that mode 3 universities are still interested in focusing on and in conducting basic research. But the mode 3 university does not assume an intrinsic contradiction between basic research and innovation (knowledge application): in fact, quite contrarily, the mode 3 university sees benefits and opportunities in a parallel (nonlinear) approach to knowledge production and knowledge application, to forms of combinations between basic research and innovation. Mode 3 universities (higher education institutions) have the opportunity of offering and developing "creative knowledge environments" (on creative knowledge environments, see Hemlin et al. 2004).

Mode 2 and mode 3 higher education institutions are the perfect organizational visà-vis of academic firms to engage in trans-sectoral networks and to perform good knowledge production. Here, a creative and innovative hybrid overlapping in regular frequency occurs or should possibly occur. This represents a coming-together and networking on equal and fair grounds. Not the universities (higher education institutions) should adapt one-sidedly to firms and their economic needs, but both sides should learn mutually from each other to the benefit of all involved parties, actors, and institutions. The assertion is: "While the entrepreneurial (mode 2) university represents a 
partial extension of business elements to the world of academia, the academic firm could serve as an example for an extension of the world of academia to the world of business. Academic firms are knowledge-oriented, interested in engaging in networks with universities (the higher education sector), encourage 'academic culture and values' to motivate their employees, allow forms of academic work (such as academic-style publishing), and support continuing education and life-long learning of and for their employees (flexible time schemes, honoring life-long learning and continued continuing education with internal career promotion)" (Carayannis and Campbell 2012, p. 27).

In organizational terms, there are several possibilities, options, and opportunities on how the academic firm can be realized and can be structured (Carayannis and Campbell 2012, p. 27):

1. "A whole firm"

2. "A subunit, subdivision, or branch of a 'commercial' firm"

3. "Certain characteristics or elements of a whole (commercial) firm"

A whole firm can be organized and designed in accordance with the principles of an academic firm. However, it is also possible only to organize subunits (branches) of a firm according to the principles of academic firms. Alternatively, the focus may be placed primarily on certain principles of an academic firm, and these principles then can be applied to or across the whole (commercial) firm or at least to substantial divisions of the whole (commercial) firm. The term "academic firm" perhaps invites us to the belief, imagination, or vision that this would always mean a whole firm. What the analysis presented here however demonstrates is that this would be an artificially narrowing-down of the concept and idea of the academic firm. It is important to note that the academic firm can address a whole firm or only specific organizational units (subunits), processes, or principles of a whole firm. In fact, this even would allow for hybrid combinations and overlapping arrangements between the academic firm (knowledge-focused and knowledge-driven) and the commercial firm (profit-driven). Currently, it is difficult to assess how common or uncommon academic firms or principles of the academic firm are in the world of contemporary business. The conventional wisdom would be that the commercial firm represents (still represents) the dominant type of organizational representation for how to structure and how to develop firms (companies). In metaphorical terms, this is also the visualized image and picture in Fig. 1. With the advancement of economy and knowledge economy in context of the knowledge society (and knowledge democracy), it is plausible to assume that expectations are justified that a diffusion and spreading of academic firms appear to be reasonable. Academic firms have all the potential of substantially transforming (in a bottom-up mode and fashion) how the economy and economic activity are being understood and processed. The academic firm invites the introduction of academic values, life styles, and working methods into business because the academic firm believes that academic research and the academic context to academic research are beneficial to the capacities and capabilities of firms focusing on knowledge production (research) and knowledge application (innovation). For the academic firm, academic research is not external but is being conceptualized, re-modeled, and incorporated as an intrinsic process and an intrinsic form of organization within the boundaries of a firm. Academic firms also 
engage in academic research, where research is linked and inter-connected with innovation. Academic firms express and encourage a "limited 'scientification' of business R\&D" (Campbell and Güttel 2005, p. 170; Campbell et al. 2013; see also Carayannis and Campbell 2009).

\section{Cross-employment}

Cross-employment represents a type of multi-employment, where a person is being employed simultaneously by more than one organization (institution). The emphasis here is placed on employment by at least two organizations, and it must be simultaneous (and not a sequential first-then) form of employment. The opposite concept to cross-employment would be the single employment by only one organization (or institution) at a time. Employment implies that the person is involved in social and tacit learning of the different organizations that also behave as organizational environments. When employment is in reference to knowledge production and knowledge application, then cross-employment should also be understood as an expression of and as a form for organizing, optimizing, and excelling research and innovation. Cross-employment already exists as an empirical phenomenon. How common or uncommon currently cross-employment is, is difficult to assess. This topic has not been sufficiently researched, so far. Beyond the empirical aspects of cross-employment, also the question could be raised, whether cross-employment has also the qualities of a normative and ideal-typical category: should work, also in association with knowledge production, research, and innovation, be organized in a way of allowing for more (or even encouraging) arrangements that follow the logic of cross-employment?

Cross-employment as a specific term and concept was first introduced by Campbell (2011 and 2013). In Carayannis and Campbell (2012), p. 24, the following comprehensive description for cross-employment is being presented: "Cross-employment (multiemployment) may be regarded as one (organizational) strategy for realizing creative knowledge environments. Cross-employment (multi-employment) refers to a knowledge worker, employee, who is being simultaneously employed by more than one organization, possibly being located in different sectors (e.g., a higher education and a non-higher education institution, e.g., a university and a firm). This supports the direct network-style coupling of very different organizations in knowledge production and innovation application, expressing, therefore, what nonlinear innovation could mean in practical terms ... Cross-employment makes possible 'parallel careers' for individuals (knowledge workers) across a diversity of organizations and sectors, thus also a simultaneous operating in parallel in organizations with different rationales and innovation cultures". The creative knowledge environments (CKEs), as a concept and term, were introduced by Hemlin et al. (2004).

Cross-employment (employment) has a hybrid overlapping or can be combined with other forms of activities that are non-employment-based (such as self-employment) or also with partial (part-time) retirement, then being called cross-retirement in connection with employment or cross-employment (Fig. 2). Ramifications of crossemployment, therefore, are not only limited to types of employment.

Cross-employment does not only have advantages, when compared with single employment. However, in the following, those characteristics of cross-employment 


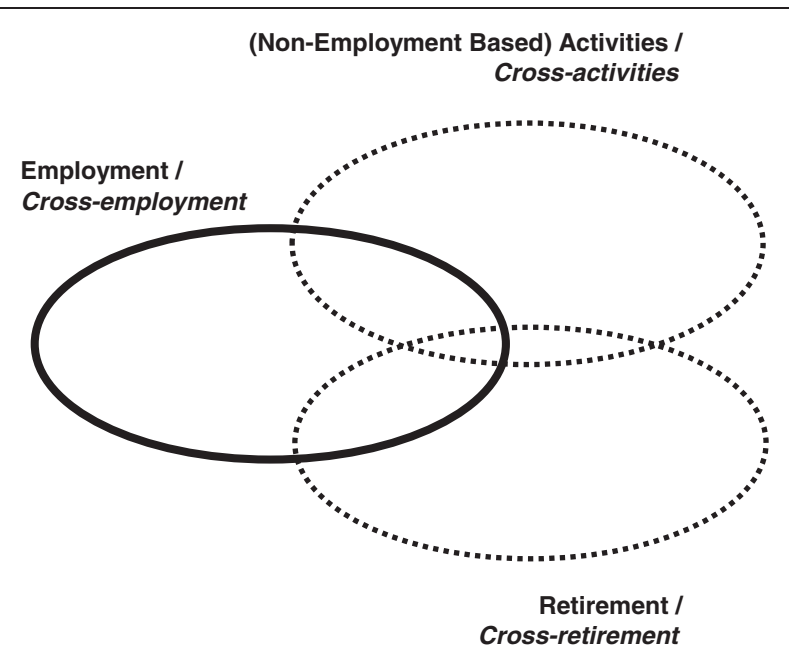

Fig. 2 The hybrid overlapping of employment and cross-employment with activities and retirement. Source: Authors' own conceptualization based on Campbell (2013)

should be elaborated in more detail, which offer opportunities and potentially also benefits to (individual) persons as well as the organization. The context for crossemployment to be discussed here are organizations (institutions) that are engaged in knowledge production and knowledge application, or research and innovation:

1. Creative development of complementary competences, diversification, and pluralization of the competence base of organizations: Persons that can base their activities of knowledge production and knowledge application on working relations of crossemployment are in a position of creatively (and innovatively) developing further complementary competences that also refer to practical experiences and tacit knowledge. For the organization, this has the potential benefit that the spectrum of competences of their employees is being diversified and pluralized to a crucial extent. This supplies evidence how cross-employment represents one approach for helping to develop "creative knowledge environments" within organizations. The combination of complementary competences also nurtures the creation of new competences. Organizations (institutions), therefore, should regard cross-employment also as an organizational opportunity for themselves.

2. Network-style formation of linkages (and bridges) across organizations and sectors: Cross-employment supports the formation and advancement of networks and network linkages between organizations (institutions). In fact, cross-employment represents a crucial form of organizational manifestation for the development and promotion of networks. For example, there can be cross-employment between two or more universities (higher education institutions), where in one case, the employee may focus on academic research and in the other case on organizational quality enhancement. In such a scenario, the cross-employment would unfold still within one sector, the higher education system. Cross-employment, however, can also create network-style connections between organizations in different sectors, for example, the higher education sector and the economy (the business enterprise sector): in such a scenario, the cross-employment would act and behave transsectorally and would perform a trans-sectoral building of linkages and bridges. 
Multiple forms, networks, and combinations of trans-sectoral cross-employment between universities (higher education institutions), university-related institutions, firms (commercial firms, academic firms), and other organizations (for example, of the civil society) are possible, feasible, and even recommendable (see Fig. 2). Crossemployed persons, across different organization and sectors, create (or at least have the potential of creating) a multitude or heterogeneity of cross-organizational and cross-sectoral networks.

3. Cross-employment as one organizational expression for non-linear innovation: The model of linear innovation is often being referred to Bush (1945). One core understanding of that model is that, first, there is basic research in a university context, which later develops further to an innovation application in context of a firm. This linear framing of innovation is being challenged by the notions of an evolving non-linear innovation. In practice, there often will be a hybrid overlapping of forms and processes of linear and non-linear innovation. This may mean that an organization (firm) engages simultaneously in different technology life cycles at different degrees (levels) of technology maturity (closer to basic research or closer to application and market commercialization). Cross-employment represents another crucial manifestation and organizational representation of and for nonlinear innovation. For example: a cross-employed person (knowledge worker) can participate in basic research at a university and, at the same time, may be involved in innovation application and knowledge practice in a firm or another organization outside of university. Such a person works simultaneously at both ends of the whole spectrum of knowledge production and knowledge application.

The concept "cross-retirement" here means (see again Fig. 2): "Cross retirement (i.e. cross-employed and cross-retired) likewise aims at allowing the individual to combine the benefits of retirement and those of work in a similar way, but with some important distinctions. Cross-retirement (a) does not constitute a transition period but rather an additional phase of life without any pre-determined endpoint, and (b) the ratio of work and free time should be self-determined and flexibly adjustable to the individual's needs. Cross-retirement thus should enable the individual to continue to contribute to society while limiting the restraints of regular employment. Cross-retirement represents a status where a person is retired and works at the same time. More precisely defined, this means that a person works (full-time, but probably more likely part-time), however also earns retirement payments, to which he or she is eligible and entitled" (Blasche and Campbell 2013, p. 508).

\section{Results and discussion}

Design (and redesign) characteristics (attributes) of the academic firm are:

1. It is knowledge-based, knowledge-creating, and innovation-oriented

2. Incorporates academic values: motivates employees and creates bonds of trust

3. Engages in networks with universities (higher education institutions, HEIs) and can access university knowledge (e.g., basic university research)

4. Allows academic research work (academic publications can act as incentives for codifying tacit knowledge) 
5. Supports and enables continued education, life-long learning, and partial absence/ leave of employees

6. Allows cross-employment (split employment) of employees with other (academic) organizations, institutions

7. It should foster "creative knowledge environments" (CKE: see Hemlin et al. 2004)

\section{Conclusions}

In search for an ideal-typical portraying of the academic firm and the concept of the academic firm, the following characteristics and principles can be listed and again summarized (designed and redesigned):

1. The academic firm is a type of firm (firm-based organization or institution) that is being driven by focusing on encouraging, supporting, and advancing knowledge production (research, research and experimental development, $R \& D$ ) and knowledge application (innovation). The academic firm is also interested in generating profits (revenues), but this should be a "sustainable profit" in comprehensive terms and well in balance with the good principles of a good knowledge production and knowledge application (innovation). The academic firm operates in a whole knowledge-based ecosystem.

2. The academic firm is and behaves knowledge-based, knowledge-oriented, knowledge-driven, knowledge-producing, and knowledge-creating. The academic firm displays (often) an inclination for applying and following the logic of nonlinear innovation, by this demonstrating flexibility. The academic firm regards basic research in the context of application as an opportunity.

3. The academic firm incorporates academic values to motivate its employees and to create bonds of trust and of a good relationship between the organization and the individual employees. The academic firm interprets and qualifies a disciplinary (interdisciplinary) variety of the background of its employees (and their competences) as a potential opportunity and asset to perform creatively in knowledge production and knowledge application.

4. The academic firm has an interest to engage in networks with universities (higher education institutions) or other academic research institutions, driven out of a desire to access university knowledge (for example, basic university research). In general, the academic firm values engagement in diversified networks as a form for creating knowledge as well as benefitting from opportunities.

5. The academic firm allows and encourages academic research work (academic publications can act as incentives for employees to codify their tacit knowledge).

6. The academic firm supports continuing education, further education, and life-long learning of its employees and has in principle a positive attitude in favor of a flexibility concerning the load of working hours and their flexible adaptation for their employees and their needs (full time, part time, perhaps shifting back-andforth) but also for partial absence or partial leave of its employees. Cross-benefitting cross-connections between careers and career schemes with continuing education are being explored by the academic firm.

7. The academic firm accepts in principle, in certain situations even promotes, split employment or "cross-employment" (multi-employment) of its employees with 
other (academic) organizations or institutions, for example, universities or other higher education institutions.

8. The academic firm is interested in creating internally "creative knowledge environments" (Hemlin et al. 2004) within the internal boundaries of its organization. The academic firm emphasizes the need of and for creativity for knowledge (knowledge production, research) and innovation.

The academic firm has the potential of transforming and changing the way how knowledge-based and knowledge-oriented economic work is being organized and performed.

However, does the academic firm represent primarily an ideal-typical concept, or does the academic firm exist (do academic firms exist) also in real terms? The commercial firm appears to define the dominant and established norm in the world of contemporary business. The empirical appropriateness or the proof of fitness for the ideas of the academic firm perhaps still needs to be demonstrated or verified. Academic firms are or would be exposed to an economic environment, where success often means to cope with and to profit from mechanisms and forces of severe competition in a continuously globalizing world. But the concept of "co-opetition" (Brandenburger and Nalebuff 1997) suggests also that success in competition means to develop networks with overlapping patterns of cooperation and competition. Between the two (conceptually) extreme poles of the academic firm and the commercial firm, many and several in-between forms of organization or hybrid combinations are possible. The academic firm represents a challenging proposition for current business. The academic firm, however, indicates also routes and paths, for how next-stage changes and future changes and future successes in the world of business and the knowledge economy (in the knowledge economy) can be approached and achieved. The academic firm is interested in bringing together innovation and entrepreneurship for development, more so for sustainable development.

The proposition here is that the academic firm represents a new design (and redesign) for entrepreneurship in innovation-driven knowledge economy.

\section{Methods}

The article follows the attempt and logic of reconstructing (by this designing) key elements of the current discourses on innovation and knowledge. For that purpose, also writing skills based on "mode 3 writing techniques" were utilized (Carayannis and Campbell 2006).

Competing interests

The authors declare that they have no competing interests.

Authors' contributions

DFJC and EGC are the authors and conceptual architects of the article and contributed in equal shares. The metaphor for this therefore is CC (creative couple). Both authors read and approved the final manuscript.

Author details

${ }^{1}$ Institute of Science Communication and Higher Education Research, Alpen-Adria-University Klagenfurt, Vienna, Austria. ${ }^{2}$ University of Applied Arts, Vienna, Austria. ${ }^{3}$ Department of Information Systems and Technology Management, School of Business, The George Washington University, Washington, DC, USA. 
References

Blasche, GWE, \& Campbell, DFJ (2013). Cross-retirement (cross-employed cross-retired) and innovation, 508-513. In Elias G. Carayannis (Editor-in-Chief). IN Dubina, N Seel, DFJ Campbell, D Uzunidis (Eds.), Encyclopedia of creativity, invention, innovation and entrepreneurship. New York: Springer. (http://link.springer.com/referenceworkentry/10. 1007/978-1-4614-3858-8_255 and http://www.springerreference.com/docs/html/chapterdbid/378720.html). Brandenburger, AM, \& Nalebuff, BJ (1997). Co-opetition. New York: Doubleday.

Bush, V (1945). Science: the endless frontier. Washington: United States Government Printing Office (http://www.nsf.gov/ od/lpa/nsf50/vbush1945.htm\#transmittal).

Campbell, DFJ (2011). Wissenschaftliche "Parallelkarrieren" als Chance. Wenn Wissenschaft immer öfter zur Halbtagsbeschäftigung wird, könnte eine Lösung im "Cross-Employment" liegen. Guest Commentary for DIE PRESSE (February 2, 2011) (http://diepresse.com/home/bildung/meinung/635781/WissenschaftlicheParallelkarrieren-als-Chance?direct=635777\&_vl_backlink=/home/bildung/index.do\&selChannel=500).

Campbell, DFJ (2013). Cross-employment, 503-508. In EG Carayannis (Editor-in-Chief), IN Dubina, N Seel, DFJ Campbell, D Uzunidis (Eds.), Encyclopedia of creativity, invention, innovation and entrepreneurship. New York: Springer. (http://link.springer.com/referenceworkentry/10.1007/978-1-4614-3858-8_254 and http://www.springerreference. com/docs/html/chapterdbid/378719.html).

Campbell, DFJ., \& Carayannis, EG (2012). Lineare und nicht-lineare Knowledge Production: innovative Herausforderungen für das Hochschulsystem. Zeitschrift für Hochschulentwicklung, 7(2), 64-72 (http://www.zfhe.at/ index.php/zfhe/article/view/448)

Campbell, DFJ, \& Carayannis, EG (2013). Epistemic governance in higher education. Quality enhancement of universities for development. SpringerBriefs in Business. New York: Springer. http://www.springer.com/business+\%26+management/ organization/book/978-1-4614-4417-6.

Campbell, DFJ, \& Güttel, WH (2005). Knowledge production of firms: research networks and the "scientification" of business R\&D. International Journal of Technology Management, 37(1/2), 152-175.

Campbell, DFJ, Carayannis, EG, \& Güttel, WH(2013). Academic firm, 17-23. In EG Carayannis (Editor-in-Chief), IN Dubina, N Seel, DFJ Campbell, D Uzunidis (Eds.), Encyclopedia of creativity, invention, innovation and entrepreneurship. New York: Springer. (http://link.springer.com/referenceworkentry/10.1007/978-1-4614-3858-8_252 and http://www. springerreference.com/docs/html/chapterdbid/378717.html).

Carayannis, EG, \& Campbell, DFJ (2006). "Mode 3": Meaning and implications from a knowledge systems perspective. In EG Carayannis \& DFJ Campbell (Eds.), Knowledge creation, diffusion and use in innovation networks and knowledge clusters (pp. 1-25). Westport: Praeger.

Carayannis, EG, \& Campbell, DFJ (2009). "Mode 3" and "quadruple helix": toward a 21st century fractal innovation ecosystem. International Journal of Technology Management, 46(3/4), 201-234. http://www.inderscience.com/ browse/index.php?journallD=27\&year=2009\&vol=46\&issue=3/4 and http://www.inderscience.com/search/index. php?action=record\&rec_id=23374\&prevQuery=\&ps=10\&m=or.

Carayannis, EG, \& Campbell, DFJ (2012). Mode 3 knowledge production in quadruple helix innovation systems. 21st-century democracy, innovation, and entrepreneurship for development. SpringerBriefs in Business. New York: Springer. http:// www.springer.com/business+\%26+management/book/978-1-4614-2061-3.

Gibbons, M, Limoges, C, Nowotny, H, Schwartzman, S, Scott, P, \& Trow, M (1994). The new production of knowledge. The dynamics of science and research in contemporary societies. London: Sage.

Hemlin, S, Allwood, CM, \& Martin, BR (2004). Creative knowledge environments. The influences on creativity in research and innovation. Cheltenham: Edward Elgar.

Nowotny, H, Scott, P, \& Gibbons, M (2001). Re-thinking science. Knowledge and the public in an age of uncertainty. Cambridge: Polity Press.

Nowotny, H, Scott, P, \& Gibbons, M (2003). Mode 2 revisited: the new production of knowledge. Minerva, 41, 179-194 Nowotny, H, Scott, P, \& Gibbons, M (2006). Re-thinking science: mode 2 in societal context. In EG Carayannis \& DFJ Campbell (Eds.), Knowledge creation, diffusion, and use in innovation networks and knowledge clusters. A comparative systems approach across the United States, Europe and Asia (pp. 39-51). Westport: Praeger.

\section{Submit your manuscript to a SpringerOpen ${ }^{\circ}$} journal and benefit from:

- Convenient online submission

- Rigorous peer review

Immediate publication on acceptance

- Open access: articles freely available online

- High visibility within the field

- Retaining the copyright to your article

Submit your next manuscript at $>$ springeropen.com 